\title{
A Relação da Motivação para o Trabalho com as Metas do Trabalhador
}

\author{
Alvaro Tamayo \\ Tatiane Paschoal
}

\section{Resumo}

O objetivo central deste artigo é propor um modelo para aprimorar programas de motivação no trabalho a partir do perfil motivacional do trabalhador. O pressuposto básico é que as estratégias de motivação laboral são mais eficientes quando correspondem diretamente a metas e valores do trabalhador. Para tanto, são discutidas brevemente as principais teorias que explicam a motivação no trabalho, bem como suas aplicações em programas motivacionais concretos. É apresentada uma moderna teoria dos valores, verificada empiricamente em mais de 60 países, que identifica a estrutura motivacional das pessoas. Com base nos resultados destes estudos, é introduzido o conceito de perfil motivacional do trabalhador e discutida a sua forma de avaliação nas organizações. É igualmente apontada a correspondência entre diversos aspectos do perfil motivacional e diversos motivadores utilizados na prática organizacional. Conclui-se que o conhecimento do perfil motivacional do trabalhador possibilita o desenvolvimento de programas diferenciados de motivação dentro da organização, visando à atender a metas de trabalhadores diversos.

Palavras-chaves: motivação no trabalho; perfil motivacional do trabalhador; teorias de motivação.

\begin{abstract}
The main objective of this paper is to propose a model for improving work motivation programs based on the worker's motivational profile. The basic principle is that the work motivational strategies are more efficient when elaborated directly from the worker's personal goals and values. In order to do that, major work motivational theories are briefly discussed as well as their application in organizational motivational programs. A modern theory of values is introduced, previously verified empirically in more the 60 countries, from which it is possible to identify people's motivational structure. On the basis of the results of those studies, the concept of the worker's motivational profile is proposed and the evaluation strategy of that profile in the organizations is discussed. The correspondence between different aspects of the motivational profile and several motivational strategies used in the organizational practice are also pointed out. It is concluded that the knowledge of the worker's motivational profile facilitates the development of differential motivational programs in the organization, responding to the goals and values of workers from different organizational sectors.
\end{abstract}

Key words: work motivation; worker's motivational profile; motivational theories. 


\section{INTRODUÇÃO}

A complexidade do trabalho nas organizações, as suas múltiplas e variadas demandas, os novos ambientes de produção e a competitividade crescente no mundo dos negócios têm como corolário a necessidade de valorizar os empregados e de criar condições favoráveis para maximizar o seu desempenho e a sua satisfação no trabalho. Atualmente, observam-se na pesquisa e na prática organizacionais, mudanças importantes nas estratégias motivacionais utilizadas nas organizações. A tendência é substituir as estratégias centradas na recompensa associada ao desempenho esperado (Steers e Porter, 1991; Schiehll e Morissette, 2000) por um estilo de vida organizacional que promova o bem-estar e a felicidade do empregado no trabalho (Erez, Kleinbeck e Thierry, 2001). A motivação laboral é uma das áreas em pesquisa e gestão de recursos humanos, que tem sido sempre orientada por uma abordagem positiva e humanizadora do ambiente de trabalho, procurando encontrar caminhos para ajudar o trabalhador a satisfazer as suas necessidades no trabalho e a se realizar profissionalmente nele. As teorias motivacionais podem ser entendidas como uma tentativa incessante e progressiva para identificar fontes de prazer que o trabalhador encontra ou pode encontrar no seu ambiente de trabalho. Essas fontes parecem encontrar-se no próprio trabalhador, no ambiente de trabalho e na interação entre os dois.

Este artigo tem como objetivo analisar e propor um modelo de motivação no trabalho a partir do perfil motivacional do trabalhador. O pressuposto básico é que as estratégias de motivação laboral são mais eficientes quando os motivadores adotados correspondem diretamente às metas e valores do trabalhador. Este estudo envolve dois conjuntos de conceitos centrais - teorias motivacionais do trabalho e perfil motivacional do trabalhador - e a tentativa de articulá-los teórica e pragmaticamente. Quanto aos fins, o estudo pode ser classificado como exploratório. Quanto aos meios, foi realizada pesquisa bibliográfica. O artigo estrutura-se nos seguintes tópicos: motivação no trabalho; perfil motivacional do trabalhador; e motivação para o trabalho a partir do perfil motivacional do empregado.

\section{Motivação no Trabalho}

A relação da motivação com o comportamento e com o desempenho é 
estabelecida espontaneamente tanto pelos cientistas como pelas pessoas leigas. O comportamento é percebido como sendo provocado e guiado por metas da pessoa, que realiza um esforço para atingir determinado objetivo. A maioria dos autores considera a motivação humana como um processo psicológico estreitamente relacionado com o impulso ou com a tendência a realizar com persistência determinados comportamentos. A motivação no trabalho, por exemplo, manifesta-se pela orientação do empregado para realizar com presteza e precisão as suas tarefas e persistir na sua execução até conseguir o resultado previsto ou esperado. Geralmente, salientam-se três componentes na motivação: o impulso, a direção e a persistência do comportamento (Mitchell, 1982; Kanfer, 1990, 1992; Katzel e Thompson, 1990; Locke e Lathan, 1990; Vallerand e Thill, 1993).

O estudo da motivação no trabalho recebe interesse considerável na literatura internacional devido, provavelmente, à sua estreita relação com a produtividade individual e organizacional. O problema da motivação no trabalho situa-se, inevitavelmente, no contexto da interação dos interesses da organização com os interesses do empregado. As duas partes envolvem-se numa parceria, na qual cada uma delas apresenta, explicita e/ou implicitamente, as suas exigências e demandas. Da parte da organização, existem demandas explícitas e bastante precisas relacionadas ao desempenho do empregado e às normas de comportamento na empresa. Em relação ao desempenho, a empresa exige que os seus membros executem tarefas bem delimitadas, em períodos determinados de trabalho e com padrões de quantidade e qualidade previamente estabelecidos. Todas estas atividades fazem parte do papel atribuído ao empregado e são, geralmente, regidas pelo próprio contrato de trabalho. Para a execução das tarefas, a empresa fornece aos seus empregados o equipamento e o material necessário, este último podendo, muitas vezes, não corresponder às exigências das tarefas e da própria organização.

As demandas da organização referem-se também ao cumprimento de normas de comportamento que regulam o convívio dos seus membros, à própria execução do trabalho e à tramitação interna dos processos ou projetos organizacionais. Além disso, existem expectativas ou demandas implícitas da empresa quanto a comportamentos espontâneos do empregado. Trata-se de comportamentos altruísticos dos empregados, que são de vital importância para o bom funcionamento da organização (Katz e Kahn, 1974). De forma geral, pode-se dizer que são atos extra-papel, que os trabalhadores executam espontaneamente e que são benéficos para o sistema organizacional. Vários comportamentos deste tipo têm sido estudados, tais como: cidadania organizacional (Smith, Organ e Near, 1983), comportamentos extra-papel (Pearce e Gregersen, 1991), comportamentos pró-social (George, 1991), espontaneidade organizacional (George e Brief, 1992) e civismo organizacional (Porto e Tamayo, 2002; Siqueira, 2002). 
Estes comportamentos apresentam em comum duas caraterísticas: eles são espontâneos e benéficos para a organização. Segundo Katz e Kahn (1974), as empresas/organizações que se baseiam exclusivamente no papel prescrito, possuem uma estrutura extremamente frágil. O comportamento espontâneo é necessário para a consecução das funções organizacionais não estabelecidas formalmente pela organização.

As demandas do empregado no ambiente organizacional referem-se, fundamentalmente, a ser tratado e respeitado como ser humano e a encontrar na organização oportunidades para satisfazer as suas necessidades e atingir os seus objetivos e expectativas por meio da própria atividade do trabalho. Quando o ser humano entra numa organização para trabalhar, o seu interesse básico não é aumentar o lucro dessa organização ou empresa, mas satisfazer necessidades pessoais de ordens diversas. Se ele não encontrar no trabalho meios de satisfazer as suas expectativas e de atingir as metas principais da sua existência, ele não se sentirá numa relação de troca, mas de exploração. O empregado aporta ao trabalho as suas habilidades e conhecimentos, a sua experiência e criatividade, o seu entusiasmo, a sua energia e a sua motivação. Na sua bagagem inicial, leva também as suas limitações, particularmente ao nível dos conhecimentos e habilidades necessários para a execução do seu trabalho.

Entre a pessoa e a organização onde ela trabalha, existe uma verdadeira dinâmica que é fundamental para a obtenção dos objetivos tanto da organização como do empregado. Esta dinâmica é determinada pelas exigências do próprio trabalho e da organização e pelas demandas do empregado (Peiró e Prieto, 1996). O equilíbrio entre as duas fontes desta dinâmica (o trabalho/empresa e a pessoa) tem conseqüências positivas tanto para a organização quanto para o empregado. Os benefícios para a organização manifestam-se na qualidade e na quantidade de trabalho executado pelo empregado. As conseqüências para ele situam-se principalmente no nível da realização pessoal, da satisfação, do bem-estar e da auto-estima. Segundo Erez (1997), empregados insatisfeitos não apresentam disposição para dedicar esforço, conhecimentos e habilidades pessoais no seu trabalho. Portanto é fundamental que a organização valorize, eficientemente, os seus empregados, se quiser manter um lugar de destaque no mercado altamente competitivo de hoje.

\section{Teorias Motivacionais e Programas de Motivação}

Numerosas teorias têm sido elaboradas para tentar explicar a motivação no trabalho. Inicialmente, as explicações eram relativamente simples, baseadas em geral numa única dimensão e não levavam em consideração a dinâmica entre o empregado e o seu trabalho. Assim, na teoria da administração científica de 
Taylor, por exemplo, considerava-se que o salário era o motivador fundamental e que ele era suficiente para obter o desempenho esperado do trabalhador. Desta forma, a partir do modelo econômico do homem foi elaborada uma teoria motivacional do trabalho. Posteriormente, muitas outras foram elaboradas, caracterizadas pela sua maior complexidade e por uma abordagem cada vez mais psico-sócio-cultural. Não é objetivo deste artigo apresentar as diversas teorias motivacionais. No Quadro 1, apresenta-se uma breve síntese das principais categorias em que podem ser classificadas as teorias motivacionais.

\section{Quadro 1: Teorias Endógenas e Exógenas de Motivação Laboral}

\begin{tabular}{|c|c|}
\hline Teorias endógenas & Pressuposto fundamental \\
\hline 1 - Arousal/atividade/energia & $\begin{array}{l}\text { Processos internos (estados fisiológicos e afetivos) } \\
\text { mediatizam o impacto das condições de trabalho } \\
\text { sobre o desempenho. }\end{array}$ \\
\hline 2 - Expectativas-valência & $\begin{array}{l}\text { As pessoas são motivadas a trabalhar quando } \\
\text { acreditam que serão capazes de obter e realizar o que } \\
\text { elas esperam do trabalho. }\end{array}$ \\
\hline 3 - Eqüidade & $\begin{array}{l}\text { As pessoas são motivadas pelas necessidades de } \\
\text { receber um tratamento eqüitativo. }\end{array}$ \\
\hline 4 - Atitude & $\begin{array}{l}\text { Indivíduos com atitudes favoráveis ao seu trabalho e à } \\
\text { sua organização serão mais motivados na execução } \\
\text { das suas tarefas. }\end{array}$ \\
\hline 5 - Intenção/metas & $\begin{array}{l}\text { O desempenho individual é determinado pelas metas } \\
\text { da pessoa. }\end{array}$ \\
\hline 6 - Atribuição e auto-estima & $\begin{array}{l}\text { A motivação é maior quando as causas do } \\
\text { desempenho são percebidas como sendo estáveis e } \\
\text { internas e a auto-estima do indivíduo é elevada. }\end{array}$ \\
\hline Teorias exógenas & Pressuposto fundamental \\
\hline 1 - Motivos /necessidades & $\begin{array}{l}\text { As pessoas possuem tendências inatas ou adquiridas a } \\
\text { buscar certos estímulos e evitar outros. }\end{array}$ \\
\hline 2 - Incentivos/recompensas & $\begin{array}{l}\text { Características da situação do trabalho levam o } \\
\text { trabalhador a associar determinadas formas de } \\
\text { comportamento com a recompensa. }\end{array}$ \\
\hline 3 - Reforço & $\begin{array}{l}\text { As pessoas são motivadas a trabalhar bem quando o } \\
\text { bom desempenho é seguido de consequiências } \\
\text { positivas. }\end{array}$ \\
\hline $4-$ Metas/objetivos & $\begin{array}{l}\text { As pessoas apresentam melhor desempenho quando } \\
\text { as metas são desafiadoras, específicas e atraentes. }\end{array}$ \\
\hline 5 - Recursos pessoais e materiais & $\begin{array}{l}\text { Condições de trabalho que facilitam a obtenção das } \\
\text { metas são fonte de motivação. }\end{array}$ \\
\hline 6 - Grupo e fatores sociais & $\begin{array}{l}\text { As pessoas apresentam melhor desempenho quando a } \\
\text { organização e os colegas facilitam a execução do } \\
\text { trabalho e reconhecem o bom desempenho. }\end{array}$ \\
\hline 7 - Sistema socio-técnico & $\begin{array}{l}\text { A motivação aumenta quando no sistema de trabalho } \\
\text { existe harmonia nas condições de funcionamento } \\
\text { pessoal, social e técnico. }\end{array}$ \\
\hline
\end{tabular}


Quando se fala de motivação laboral, existem dois grandes conjuntos de teorias motivacionais. O primeiro compreende as teorias relacionadas com aspectos motivadores do trabalho, denominadas por Katzell e Thompson (1990) como teorias exógenas. Estas teorias focalizam aspectos do trabalho relevantes para valorizar e estimular a pessoa no trabalho. Geralmente, dois conjuntos de aspectos ou fatores são utilizados: o conteúdo do trabalho e as características do ambiente laboral. Obviamente, estes fatores podem ser modificados pela organização por meio das suas estratégias de gestão. $\mathrm{O}$ segundo grupo compreende as teorias relacionadas com as motivações pessoais. São as chamadas teorias endógenas que, segundo Katzell e Thompson (1990), exploram os processos ou variáveis mediadoras do comportamento motivado. Campbell et al. (1970) propuseram uma classificação das teorias deste grupo, utilizando como critérios o conteúdo e o processo da motivação. As teorias centradas no conteúdo tratam de identificar construtos fundamentais que motivam a atividade humana e, em conseqüência, a atividade laboral. As necessidades constituem o construto mais utilizado nestas teorias (Maslow, 1954; McClelland, 1985). As teorias centradas no processo tentam compreender e explicar o processo motivacional que determina a direção e a persistência do comportamento. Os construtos mais utilizados são os valores, as expectativas, as intenções e as atribuições (Vroom, 1964; Adams, 1965; Locke e Latham, 1990).

Segundo Katzell e Thompson (1990), apesar dos enormes progressos realizados na compreensão da motivação laboral, ainda existe longo caminho a percorrer neste sentido e, particularmente, na aplicação dos conhecimentos adquiridos. Eles concluem seu artigo sobre programas de motivação a partir das teorias exógenas, salientando quatro aspectos que merecem especial atenção nas pesquisas futuras e nas tentativas de aplicação. Um deles refere-se à necessidade de "prestar mais atenção às diferenças individuais". Segundo os autores, as teorias têm focalizado principalmente os determinantes ambientais das atitudes e do comportamento e, pouco, as disposições, interesses, valores e metas do indivíduo que podem determinar os níveis de energia que eles investem no trabalho.

Qual é a relação das teorias referentes aos fatores motivadores do trabalho com aquelas referentes às motivações pessoais? Poucos autores têm tentado uma integração destas duas abordagens. Uma tentativa integradora foi realizada por Kanfer (1992). Esta autora classificou as teorias a partir da maior ou menor proximidade dos construtos utilizados por cada uma delas com a ação. Desta forma, criou uma espécie de contínuo, no qual as teorias foram dispostas de forma decrescente em função da proximidade ou distância dos seus construtos em relação à ação. Kanfer (1990), ao terminar o seu extenso capítulo sobre as teorias motivacionais na psicologia industrial e organizacional, afirma que o progresso nesta área não será obtido por meio do aprofundamento das teorias 
tradicionais. Novas perspectivas e a sua integração com as abordagens tradicionais são necessárias. Segundo Kanfer (1990, p. 157), “a direção mais promissora para uma síntese implica na reconsideração do construto de metas, já que este permeia o funcionamento diário e a longo prazo no contexto do trabalho”.

Qual é a contribuição das teorias endógenas para a elaboração de programas motivadores na empresa? Segundo Katzell e Thompson (1990), as teorias endógenas explicam a dinâmica da motivação, mas são as teorias exógenas que sugerem ações que podem ser feitas para mudar a motivação no trabalho. Na prática, as teorias endógenas, que lidam com as motivações dos empregados, ficam no nível teórico e são as teorias exógenas que fornecem os elementos de base para definir os programas de motivação para o trabalho. Isto porque as últimas lidam com características do trabalho que podem ser modificadas por agentes externos, tais como oportunidades de promoção, condições de trabalho e enriquecimento da tarefa. Apesar da eficiência dos motivadores deduzidos a partir das diversas teorias exógenas, pode acontecer que, numa situação determinada, eles não respondam às expectativas e às metas dos empregados de uma organização. Qual é a relação das metas, interesses e motivos do trabalhador com as estratégias motivacionais utilizadas na empresa? É relevante encontrar uma forma para harmonizar os motivadores organizacionais com as metas e interesses concretos dos empregados?

Como valorizar os empregados no trabalho a partir das suas disposições, das suas metas e interesses? Como determinar os níveis potenciais de energia que os empregados podem investir no trabalho? Os programas ou estratégias geralmente utilizados nas empresas para estimular o empregado têm sido elaborados, e continuam sendo realizados, a partir das diversas teorias científicas, algumas delas verificadas por meio de pesquisa empírica. Isto significa que esses programas têm fundamentos sólidos. Contudo, na elaboração de programas organizacionais de motivação, tem-se negligenciado as diferenças individuais, como foi salientado por Katzell e Thompson (1990), pois mesmo aquelas teorias que focalizam os motivos pessoais, fazem-no no contexto da adaptação da pessoa ao seu ambiente de trabalho. Desta forma, os programas motivacionais são elaborados a partir de pressupostos teóricos gerais, universais, abstratos, sem levar diretamente em consideração as motivações pessoais dos membros da empresa.

É possível utilizar como base para a definição e elaboração de qualquer procedimento de valorização dos empregados o seu perfil motivacional? Isto é, há possibilidade de se utilizar as metas e interesses principais relativos ao trabalho e à vida como um todo? É evidente que se as tentativas da organização para valorizar os seus empregados são realizadas a partir de informações concretas sobre o que eles pretendem atingir na vida e no trabalho, elas podem ser muito 
mais eficientes do que aquelas baseadas em princípios gerais e abstratos. Obviamente, um programa de motivação não pode atender às metas e aos interesses de cada um dos empregados, mas pode ser elaborado a partir de metas e interesses compartilhados na organização como um todo ou em seus diversos setores.

Recentemente, Erez, Kleinbeck e Thierry (2001) mostraram que a motivação para o trabalho deve ser analisada nos níveis individual, grupal, organizacional e mesmo cultural. Com a abordagem multinível, a motivação no trabalho pode ser definida e analisada no nível do indivíduo, das equipes, dos grupos ou setores organizacionais e da organização como um todo, compreendendo assim os níveis micro, meso e macro. Cada vez mais nas organizações, executam-se muitas tarefas em equipe. A distribuição das tarefas em equipes muda a unidade de responsabilidade pela execução do trabalho do indivíduo para a equipe, introduzindo uma série de processos que não existem no nível individual, tais como cooperação, coordenação e conflito, mas que são altamente relevantes para o desempenho da equipe. Atualmente, mais do que nunca, a efetividade organizacional depende de pessoas que trabalham em equipe (Ilgen, 1994; Ilgen e Sheppard, 2001).

Por outra parte, a estrutura organizacional tem sido sempre composta por setores ou grupos de trabalho. Freqüentemente, estes setores apresentam características específicas decorrentes não somente da natureza dos problemas por eles tratados, mas também de crenças, valores, interesses e motivações compartilhados pelos seus membros. É evidente que a efetividade dos grupos ou setores organizacionais é influenciada por este tipo de fatores, que não existe no nível individual (Kleinbeck, Wegge e Schmidt, 2001). Contudo, a maioria dos programas motivacionais elaborados e implantados nas organizações são genéricos, válidos para todos os seus membros, sem especificidade para equipes ou setores organizacionais. Idealmente, um programa organizacional de motivação laboral não deveria ser constituído exclusivamente por aspectos gerais, válidos para toda a organização; deveria contemplar também aspectos específicos para os diversos setores organizacionais, de acordo com o perfil motivacional dos seus membros.

\section{Estrutura Motivacional e Perfil Motivacional}

Quais são os núcleos motivacionais mais relevantes da pessoa? Como estes núcleos podem ser identificados? Eles são universais ou tributários da cultura de cada sociedade? O que é o perfil motivacional de um indivíduo? Estas interrogações referem-se a duas categorias de problemas: a primeira relativa à natureza 
motivacional da pessoa e a segunda ao perfil motivacional. A estrutura motivacional de uma pessoa consiste no conjunto de motivações ou metas que dinamizam o seu comportamento e nas relações existentes entre essas motivações. O perfil motivacional refere-se à importância que têm, para cada pessoa, as diversas motivações que orientam a sua vida. Desta forma, a estrutura motivacional constitui a base ou a matriz para a elaboração do perfil motivacional.

Um modelo de estrutura motivacional foi elaborado e verificado empiricamente por Schwartz (1992, 2001) por meio de pesquisa transcultural realizada em mais de 60 países. Os resultados apontam para a universalidade desta estrutura. Nessas pesquisas, foram postuladas diversas motivações, submetidas à verificação empírica. As diversas motivações foram identificadas por meio das prioridades dadas pelas pessoas aos valores. Qual é a relação dos valores com as motivações individuais? O ponto de partida é que os valores são representações cognitivas de necessidades e motivos (Locke, 1991). Segundo Rokeach (1973), “o homem é o único animal” capaz de realizar esse tipo de representações. Além disso, os valores representam não somente as necessidades individuais, mas também as exigências e demandas culturais. Na seqüência motivacional, os valores medeiam a relação das necessidades com as metas do indivíduo. Segundo Locke (1991), a seqüência motivacional completa compreende as necessidades na origem do processo, representadas cognitivamente pelos valores que, por sua vez, medeiam as metas e intenções. Estas últimas são antecedentes do comportamento, que é seguido de algum tipo de recompensa, o qual dá origem à satisfação. A função dos valores no processo motivacional é fundamental, pois eles fornecem significado cognitivo e cultural às necessidades, transformando-as em metas e intenções. Erez (1997, p.205) afirma que como estas últimas são conscientes, "as necessidades não podem ser transformadas em metas, a menos que elas tenham uma representação cognitiva por meio dos valores". As metas e intenções regulam os três elementos básicos da motivação: intensidade, direção e persistência do esforço.

Assim, os valores apresentam forte dimensão motivacional. Antes da existência da psicologia como ciência, os filósofos já tinham salientado a dimensão motivacional dos valores, vinculado-os à vontade (Nietzsche, 1970) e ao desejo (Lavelle, 1951). Na área da psicologia, os autores falam de necessidades em vez de desejo. Vários deles colocam a fonte dos valores em exigências ou necessidades universais do ser humano (Rokeach, 1973; Schwartz e Bilsky, 1987). Assim, os valores são considerados como metas motivacionais, que expressam alvos que a pessoa quer atingir na sua vida. Schwartz e Bilsky (1990), com base nesta perspectiva, postularam várias motivações subjacentes aos valores das pessoas. Os resultados de pesquisas interculturais realizadas em numerosos países de todos os continentes identificaram dez motivações, praticamente presentes em todos os países participantes, sugerindo a quase universalidade dessa tipologia 
motivacional (Schwartz, 1992, 1994; Tamayo e Schwartz, 1993). O Quadro 2 apresenta as dez motivações, bem como as suas metas específicas. Como pode ser observado no quadro, as metas dos cinco primeiros tipos motivacionais visam alvos que se relacionam direta e fundamentalmente com a própria pessoa, tais como o prazer, o sucesso e o prestígio. As metas dos tipos motivacionais tradição, conformidade e benevolência visam a satisfazer interesses mais diretamente relacionados com a família, a organização e a sociedade. Finalmente, as metas de universalismo e segurança referem-se a interesses tanto da própria pessoa como dos outros.

\section{Tabela 2: Motivações do Empregado e Metas motivacionais.}

\begin{tabular}{|l|l|}
\hline \multicolumn{1}{|c|}{ MOTIVAÇAO } & \multicolumn{1}{c|}{ METAS MOTIVACIONAIS } \\
\hline Autodeterminação & $\begin{array}{l}\text { Ter autonomia, decidir por si mesmo e/ou participar nas decisões, } \\
\text { controlar a organização e execução do seu trabalho. }\end{array}$ \\
\hline Estimulação & $\begin{array}{l}\text { Ter desafios na vida e no trabalho, explorar, inovar, ter emoções fortes } \\
\text { na vida e no trabalho, adquirir conhecimentos novos }\end{array}$ \\
\hline Hedonismo & $\begin{array}{l}\text { Procurar prazer e evitar a dor e o sofrimento, ter satisfação e bem-estar } \\
\text { no trabalho. }\end{array}$ \\
\hline Realização & $\begin{array}{l}\text { Ter sucesso pessoal, mostrar a sua competência, ser influente, se } \\
\text { realizar como pessoa e como profissional. }\end{array}$ \\
\hline Poder & $\begin{array}{l}\text { Ter prestígio, procurar status social, ter controle e domínio sobre } \\
\text { pessoas e informações. }\end{array}$ \\
\hline Segurança & $\begin{array}{l}\text { Integridade pessoal e das pessoas íntimas, segurança no trabalho, } \\
\text { harmonia e estabilidade da sociedade e organização em que trabalha. }\end{array}$ \\
\hline Conformidade & $\begin{array}{l}\text { Controlar impulsos, tendências e comportamentos nocivos para os } \\
\text { outros e que transgridem normas e expectativas da sociedade e da } \\
\text { organização. }\end{array}$ \\
\hline Tradição & $\begin{array}{l}\text { Respeitar e aceitar idéias e costumes tradicionais da sociedade e da } \\
\text { empresa. }\end{array}$ \\
\hline Benevolência & Procurar o bem-estar da família e das pessoas do grupo de referência. \\
\hline Universalismo & $\begin{array}{l}\text { Compreensão, tolerância, procura do bem-estar de todos na sociedade e } \\
\text { na organização onde trabalha, proteção da natureza. }\end{array}$ \\
\hline
\end{tabular}

Esses dez tipos motivacionais expressam a estrutura motivacional do indivíduo. Esta estrutura é composta por conjuntos motivacionais, que parecem estar presentes em indivíduos de todas as culturas. Cada conjunto motivacional tem metas específicas. A estrutura motivacional não é estática; ela é dinâmica e os seus componentes motivacionais relacionam-se entre si por meio de diversas polaridades. As tendências motivacionais da pessoa nem sempre são harmoniosas; algumas podem ser conflituosas, dando origem a conflitos internos. A estrutura motivacional e a dinâmica dos seus componentes foram estudadas empiricamente por meio do método da análise do espaço menor (smallest space analysis), a qual consiste numa técnica de análise estatística multidimensional indicada para determinar a estrutura da similaridade de dados. Os resultados desta análise revelam, nas mais diversas culturas, a existência de dez tipos motivacionais e a 
sua disposição no espaço multidimensional, que, por sua vez, sugere relações dinâmicas entre eles (vide Figura 1). Os cinco tipos motivacionais que expressam metas e interesses individuais (autodeterminação, estimulação, hedonismo, realização e poder social) ocupam, no espaço multidimensional, áreas contíguas opostas àquelas reservadas aos tipos motivacionais que expressam primariamente metas e interesses coletivos (benevolência, tradição e conformidade). Os tipos motivacionais segurança e universalismo, constituídos por metas e interesses tanto individuais quanto coletivos, são opostos e situam-se nas fronteiras destas duas áreas. Schwartz (1994) postula compatibilidade entre os tipos motivacionais que são adjacentes no espaço multidimensional (por exemplo, estimulação e hedonismo, tradição e conformidade) e conflito entre as metas motivacionais dos tipos situados em direções opostas (por exemplo, estimulação e conformidade, hedonismo e tradição). A busca simultânea de alvos pertencentes a áreas adjacentes é compatível porque esses alvos satisfazem interesses afins, enquanto que a procura de alvos pertencentes a motivações opostas pode ser conflitante, já que estas visam interesses díspares.

Figura 1: Estrutura Motivacional

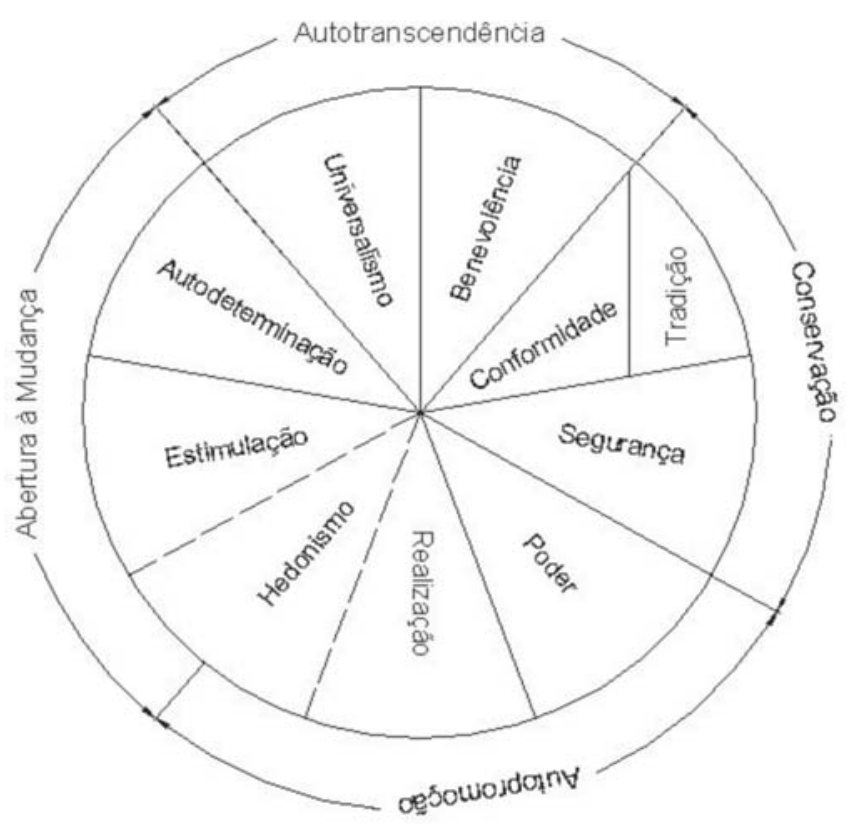

As pesquisas têm mostrado que os dez tipos motivacionais sintetizam-se em duas dimensões bipolares (vide Figura 1). Esta estruturação da motivação tem sido verificada repetidas vezes em numerosas culturas de todos os continentes e, atualmente, é considerada como sendo universal (Schwartz, 1992, 1994, 2001). 
No Brasil, vários estudos têm mostrado a sua validade (Tamayo e Schwartz, 1993; Tamayo, 1994). A primeira dimensão, procura de mudança versus estabilidade, expressa a motivação da pessoa para seguir os seus próprios interesses intelectuais e afetivos por meio de caminhos incertos e ambíguos, em oposição à tendência a procurar a estabilidade e a preservar o status quo e a segurança que ele gera no relacionamento com os outros e com as instituições. Teoricamente, situam-se, num dos pólos deste eixo, os tipos motivacionais estimulação e autodeterminação e, no outro, os referentes aos tipos segurança, conformidade e tradição. Assim, num extremo desta dimensão encontra-se a motivação para inovar, criar, descobrir, se autodeterminar, ter autonomia e ter desafios na vida e no trabalho. No extremo oposto, encontram-se as forças motivacionais que levam a pessoa à procura de segurança, de ordem social, de autocontrole, de moderação, de estabilidade e de respeito pela tradição. A segunda dimensão, autotranscendência versus autopromoção, apresenta, num dos extremos, os tipos motivacionais universalismo e benevolência e, no outro, poder, realização e hedonismo. Este eixo expressa a motivação da pessoa para transcender as suas preocupações egoístas e promover o bem-estar dos outros e da natureza, em oposição a promover os seus próprios interesses mesmo às custas dos outros. Um dos pólos está marcado pela motivação do empregado com os resultados do grupo, da sua área, da organização como um todo. No outro pólo, a ênfase é com os seus próprios resultados, sem preocupação com os resultados coletivos, numa luta para ser melhor que os outros, para ter prestígio, influência e poder. Esta dimensão também pode ser denominada altruísmo versus prestígio.

As dimensões são bipolares e os seus pólos expressam um ponto extremo de uma determinada motivação. O eixo que sustenta os dois pólos constitui, então, um contínuo motivacional para representar a intensidade concreta que estas duas motivações opostas apresentam nas pessoas. O eixo da primeira dimensão, procura de mudança versus estabilidade, expressa um contínuo, que permite representar a intensidade ou importância dada pelas pessoas a estes dois conjuntos de motivações. Certos indivíduos podem se situar no extremo esquerdo deste contínuo, manifestando forte necessidade de desafios e de mudança. Para outros, esta necessidade pode ser menos forte, situando-se assim mais à direita do contínuo. No extremo oposto, encontram-se aqueles que sentem grande necessidade de estabilidade, tanto no contexto físico como social. A dimensão altruísmo versus prestígio representa também um contínuo, o qual organiza os indivíduos em função das suas motivações procurar o sucesso do grupo, da organização como um todo ou o seu sucesso pessoal, construído sem grande preocupação pelos interesses organizacionais, colocando os interesses da organização em segundo plano e aproveitando o nome e a estrutura dela para se projetar em primeiro plano.

Esta abordagem oferece um leque motivacional bastante variado, com metas 
referentes a praticamente todos os aspectos mais significativos da vida quotidiana e da atividade laboral. Esta característica é bastante útil para a compreensão e predição do comportamento. É uma abordagem que permite uma avaliação bastante diferenciada por meio de dez motivações, cada uma delas com metas específicas. Além disso, estas motivações apresentam uma organização dinâmica, determinada pela natureza dos interesses visados, que facilita a predição do comportamento a partir da estrutura motivacional da pessoa. Por exemplo, as pessoas que apresentam forte motivação hedonística, geralmente, são menos propensas ao controle de impulsos pessoais que destoam das normas do grupo. Estudos empíricos realizados por meio de regressão múltipla têm mostrado a relação consistente da dinâmica motivacional com a predição do comportamento no trabalho e na vida em geral (Tamayo 2000, 2001, 2002; Tamayo et al., 2001; Porto e Tamayo, 2002).

A estrutura motivacional serve de base para a elaboração do perfil motivacional, que consiste na importância relativa que cada uma das motivações tem para cada pessoa. O perfil implica, portanto, numa hierarquia de importância entre as diversas motivações do trabalhador. Desta forma, pode-se determinar quais são as motivações e metas mais importantes para ele, bem como aquelas que ocupam um segundo ou terceiro plano. Além disso, a análise detalhada da motivação pessoal pode ser completada por meio da integração das dez motivações na estrutura bidimensional, que permite uma visão mais global, e talvez mais consistente, da organização e direção das forças motivacionais do empregado.

\section{Motivação Laboral e Perfil Motivacional}

Uma organização, segundo Schein (1978), é a coordenação racional das atividades de determinado número de pessoas, que perseguem uma finalidade e um objetivo comum e explícito mediante a divisão de funções e do trabalho. Dois elementos são fundamentais nesta descrição: as organizações estão compostas por pessoas e grupos de pessoas e as organizações existem para obter fins específicos, tais como a eficiência econômica e a produtividade. Tanto o indivíduo quanto a organização apresentam as suas condições, exigências e demandas para interação mútua, mas também ambos aportam recursos específicos, essenciais para o bom funcionamento da empresa. A complexa relação das pessoas que compõem a organização com a obtenção dos seus fins específicos passa pela valorização recíproca. A valorização do empregado, por parte da empresa, fundamenta-se no reconhecimento do valor que o trabalho tem em sim mesmo e no reconhecimento da sua relevância no contexto da obtenção dos fins específicos 
da organização. A melhor forma de valorizar o empregado parece consistir em lhe oferecer oportunidades para que, por meio do seu trabalho, ele possa atingir as suas metas pessoais. Por natureza, o trabalho é uma estratégia de realização pessoal.

O Quadro 3 oferece algumas perspectivas de valorização do empregado que correspondem às suas metas e interesses. Assim, por exemplo, a motivação de autodeterminação, que visa a poder definir por si mesmo o seu caminho na vida e no trabalho, corresponde à autonomia, que consiste na possibilidade outorgada ao empregado de agir de forma relativamente independente na execução do seu trabalho, abrindo perspectivas para inovar, criar e aprimorar rotinas de execução do trabalho. Geralmente, a motivação para a autodeterminação é fonte de grandes frustrações do trabalhador, algumas delas inevitáveis, por causa de restrições impostas pela própria natureza de certos trabalhos e pelo convívio com outras pessoas. Ela é também fonte de profunda satisfação quando a organização, como forma de valorizar o empregado, lhe oferece o máximo de autonomia possível na execução do seu trabalho. A autonomia, junto com o caráter desafiador e interessante do trabalho, é um elemento fundamental também para que o trabalhador encontre prazer no trabalho, satisfazendo assim a sua motivação hedonística. O Quadro 3 apresenta perspectivas específicas para cada uma das motivações do empregado. Compõe este quadro a maioria dos motivadores que têm sido utilizados nas organizações no decorrer do tempo.

\section{Tabela 3: Demandas Motivacionais do Empregado e Perspectivas para a sua Valorização por parte da Empresa}

\begin{tabular}{|l|l|}
\hline \multicolumn{1}{|c|}{ Demandas } & \multicolumn{1}{c|}{ PERSPECTIVAS DE VALORIZAÇÃO } \\
\hline Autodeterminação & Autonomia na execução das tarefas, controle na execução do trabalho. \\
\hline Estimulação & Trabalho interessante, variado, desafiador, criativo. \\
\hline Hedonismo & Atividades prazerosas associadas ao trabalho. \\
\hline Realização & $\begin{array}{l}\text { Treinamento, desenvolvimento profissional, promoções e avanços na } \\
\text { carreira, gerenciamento do desenvolvimento profissional. }\end{array}$ \\
\hline Poder & $\begin{array}{l}\text { Prestígio dos papeis e tarefas laborais, participação nas decisões, } \\
\text { reconhecimento do mérito. }\end{array}$ \\
\hline Segurança & Estabilidade no emprego, transparência, seguro médico. \\
\hline Conformidade & $\begin{array}{l}\text { Socialização organizacional, supervisão adequada, sistema de controle } \\
\text { eficiente e justo, redução da incerteza do comportamento. }\end{array}$ \\
\hline Tradição & $\begin{array}{l}\text { Normas claras e precisas, divulgação das informações relacionadas com o } \\
\text { trabalho. }\end{array}$ \\
\hline Benevolência & Proteção familiar, atividades que envolvem a família. \\
\hline Universalismo & Clima organizacional harmônico, respeito da natureza. \\
\hline
\end{tabular}


Como foi mencionado anteriormente, as dez motivações do empregado apresentam uma estrutura bidimensional. Os quatro pólos que constituem estas duas dimensões representam motivações da pessoa e definem quatro conjuntos motivacionais fundamentais que podem ser utilizados para a gestão da motivação no trabalho. A Figura 2 ilustra esta relação. O pólo da procura de mudança expressa expectativas e metas que podem muito bem ser atingidas por meio da autonomia dada ao trabalhador para executar o seu trabalho, oferecendo-lhe assim oportunidades para criar e inovar. Neste contexto, incluem-se também o horário flexível e a responsabilidade pelos resultados esperados. O trabalho enriquecido, atraente, variado, interessante e desafiador constitui também uma forma excelente de atender às exigências desta motivação. A participação nas decisões organizacionais abre igualmente um espaço para que o empregado possa atingir suas metas de autodeterminação.

No pólo oposto, situam-se interesses e expectativas da pessoa relativos à estabilidade da organização. A segurança do trabalho e no trabalho, salário, normas e objetivos claros e precisos, círculos de qualidade, espaço físico adequado, horário regular e condições favoráveis para a execução do trabalho, constituem ações organizacionais adequadas para atender às expectativas e metas relacionadas com este pólo motivacional.

O pólo que expressa a motivação altruística focaliza fundamentalmente os resultados coletivos e o bem-estar de todos na organização. As metas referentes a esta motivação podem ser atingidas por meio de um ambiente social agradável, sem conflitos, com oportunidades para interagir com colegas e clientes. As ações concretas da empresa para manter um clima organizacional saudável, de tolerância e de colaboração também atendem às expectativas que têm fonte nesta motivação. As preocupações organizacionais com a imagem social da empresa e com o respeito à natureza constituem igualmente motivadores voltados para os empregados que possuem forte motivação altruística.

Finalmente, o pólo do prestígio, que expressa principalmente metas relacionadas com resultados pessoais, exige ações organizacionais tais como as relacionadas com incentivos financeiros, benefícios, oportunidades de promoção e reconhecimento do mérito. Treinamento e oportunidades para utilizar conhecimentos e habilidades também constituem uma forma de atender a expectativas e metas deste pólo motivacional. 


\section{Figura 2: Correspondência entre Motivações de Ordem Superior e Algumas Estratégias de Motivação Laboral}

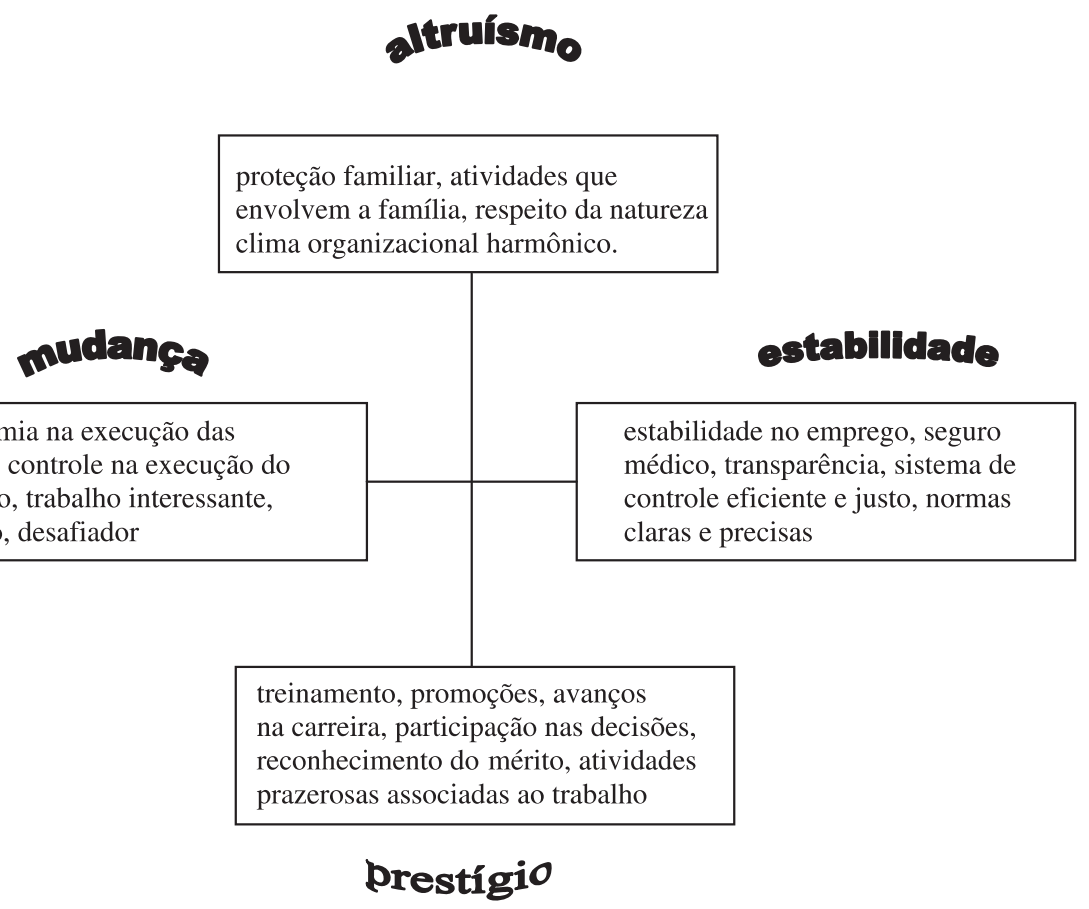

Como se pode observar na Figura 2, os programas ou estratégias utilizados nas organizações para valorizar os empregados (Katzell e Thompson, 1990) relacionam-se, especificamente, com uma ou outra das motivações de ordem superior representadas nos quatro pólos motivacionais. Esta relação da estrutura motivacional do empregado com as estratégias de motivação abre uma perspectiva interessante, no sentido de poder adequar as ações organizacionais ao perfil motivacional dos trabalhadores, respeitando não somente o conteúdo das suas motivações, mas também a sua intensidade. Por exemplo, se na organização ou num setor determinado dela predomina entre os empregados a motivação para procura de mudança e de variedade, as formas de valorização mais adequadas são aquelas que melhor atendem às metas dessa motivação, isto é, aquelas relacionadas com características internas do próprio trabalho, tais como a autonomia para a sua execução e as características da própria tarefa. Pelo contrário, se a motivação mais acentuada entre os empregados de um outro setor for a procura de resultados coletivos, as estratégias de valorização mais apropriadas são aquelas relacionadas com um clima de tolerância às idéias e opiniões dos outros, clima organizacional harmônico, preocupação com a qualidade de vida no trabalho e aspectos sociais do trabalho. 
Para viabilizar a adequação entre o perfil motivacional do trabalhador e ações concretas de motivação é necessário, porém, poder determinar com precisão o perfil motivacional dos empregados para, a partir daí, identificar as motivações predominantes e compartilhadas na empresa ou em setores dela. Atualmente existem dois instrumentos apropriados para este tipo de avaliação: o Inventário de Valores de Schwartz (IVS) e o Questionário de Perfis de Valores (QPV). Os dois foram psicometricamente validados em numerosos países, até mesmo no Brasil. O primeiro é um instrumento composto por 61 itens, adequado para ser utilizado com sujeitos com nível de escolaridade a partir do segundo grau. O QPV é muito mais simples, composto por 40 itens. Ele pode ser aplicado em sujeitos com nível de escolaridade mais baixo. Os dois instrumentos são autoadministrados e a sua correção é simples. Desta forma, a elaboração do perfil motivacional do trabalhador pode ser realizada com precisão e, a partir daí, podemse elaborar estratégias de motivação para o trabalho.

Na prática, quais são os passos principais na elaboração de um programa motivacional para uma empresa ou para um setor determinado dela, levando em consideração o perfil motivacional dos empregados? O primeiro passo é identificar o perfil motivacional dos empregados da empresa utilizando algum dos instrumentos atualmente disponíveis. Como este perfil difere entre os membros da organização, é preciso verificar os interesses e metas que são compartilhados. Para tanto, utilizam-se os escores médios obtidos pelos empregados da empresa nos diversos tipos motivacionais, de forma a determinar as motivações ou metas que são prioritárias para os empregados. Esta análise pode ser realizada no nível global, no nível de cada um dos setores da empresa e, até mesmo, no nível das equipes. Para determinar as estratégias motivadoras mais apropriadas para cada setor e/ou equipe, dois procedimentos podem ser sugeridos. O primeiro, o mais simples, consiste em escolher, entre os motivadores apresentados no Quadro 3 e na Figura 2, o(s) mais adequado(s) para cada setor em função do perfil motivacional dos seus participantes. Esta abordagem está baseada na correspondência entre as metas prioritárias dos trabalhadores e uma ou mais estratégias de motivação já utilizadas no ambiente empresarial. O segundo método é mais dinâmico e consiste em discutir com uma amostra de trabalhadores do setor alvo estratégias de motivação que eles gostariam que fossem implantadas no ambiente de trabalho. Este método tem a vantagem de contar com a participação dos trabalhadores, além do menu de motivadores do Quadro 3. Esta abordagem é potencialmente inovadora, na medida em que pode levar à definição de estratégias específicas para uma empresa ou setor e de estratégias que não têm sido utilizadas anteriormente, constituindo, neste sentido, uma contribuição para a gestão motivacional dos trabalhadores. 


\section{Conclusão}

A desvinculação entre metas do trabalhador e estratégias de motivação laboral pode ser um fator relevante no insucesso relativo de alguns programas de motivação. O conhecimento do perfil motivacional do trabalhador possibilita o desenvolvimento de programas diferenciados de motivação dentro da organização, visando à atender metas de diversos grupos de trabalhadores. Como já foi salientado, isso não quer dizer que para cada funcionário seria necessário desenvolver um programa específico, mas que os programas motivacionais passariam a considerar as especificidades de diferentes equipes e/ou setores organizacionais. Desta forma, ao invés de um único programa para toda uma organização, estratégias mais específicas e diretivas seriam desenvolvidas, visando à atingir os interesses dos grupos alvo. Ainda que a organização como um todo não esteja interessada em desenvolver diferentes estratégias motivacionais para seus vários setores, esta perspectiva permite que cada gestor implante seu próprio programa para seus trabalhadores. Isto é, o gestor que desejar, pode desenvolver um programa de motivação que atinja diretamente as metas e valores dos trabalhadores pelos quais é responsável, sem depender de programas que estejam sendo desenvolvidos por outros departamentos e unidades da organização. Para tanto, a aplicação do IVS ou do QPV fornece o perfil motivacional dos indivíduos integrantes de sua equipe ou setor e, a partir das metas representativas deste grupo, as estratégias motivacionais podem ser traçadas.

A possibilidade de relacionar motivação no trabalho com o perfil motivacional dos trabalhadores preenche diversas lacunas deixadas pelos programas que se baseiam nas abordagens exógenas ou endógenas de motivação. Na proposta aqui apresentada, as motivações pessoais não ficam exclusivamente no nível teórico; elas passam a fornecer os elementos básicos para a definição dos programas de motivação laboral. Assim os fatores exógenos da motivação podem ser utilizados de forma a alcançar motivações pessoais dos empregados.

\section{ReferênCIAS Biblográficas}

ADANS, J. S.

Inequity in social exchange. In: BERKOWITZ, L. (Ed.).

Advances in experimental social psychology. New York: Academic Press, 1965. v. 2. p. 233-256.
CAMPBELL, J. P. et al.

Managerial

behavior, performance and effectiveness. New York: McGraw-Hill, 1970. 
EREZ, M.

A culture-based model of work motivation. In: EARLY, C.; EREZ, M. (Eds.). New perspectives on international industrial/ organizational psychology. San Francisco: The New Lexington Press, 1997. p. 193-242.

EREZ, M.;

KLEINBECK, U.;

THIERRY, H.

Work motivation in the context of a globalizing economy. London: Lawrence Erlbaum, 2001.

\section{GEORGE, J. M.}

State or trait: effects of positive mood on prosocial behaviors at work. Journal of Applied Psychology, v. 76, p. 299-307, 1991.

\section{GEORGE, J. M.;}

BRIEF, A. P.

Feeling good-doing good: a conceptual analysis of the mood at work-organizational spontaneity relationship. Psychological Bulletin, v. 112, p. 310-329, 1992.

ILGEN, D. R.

Job and roles: accepting and coping with the changing structure of organization. In: RUMSEY, G.; WALKER, C. B.; HARRIS, J. H. (Eds.). Personnel section and classification. London: Lawrence Erlbaum, 1994. p. 13-22.
ILGEN, D. R.;

SHEPPARD, L.

Motivation in work teams. In:

EREZ, M.; KLEINBECK, U.; THIERRY, H. Work motivation in the context of a globalizing economy. London: Lawrence Erlbaum, 2001. p. 169-179.

KANFER, R.

Motivation theory in industrial and organizational psychology. In: DUNNETTE, M. D.; HOUGH, L. M. (Eds.). Handbook of industrial and organizational psychology. Palo Alto: Consulting Psychologist Press, 1990. v. 1. p. 75-170.

Work motivation: new directions in theory and research. In: COOPER, C. L.; ROBERTSON, I. T. (Eds.). International review of industrial and organizational psychology. New York: John Wiley \& Sons, 1992. p. 1-53.

KATZ, D.;

KAHN, R. L.

Psicologia social das organizações. São Paulo: Atlas, 1974.

KATZELL, R. A.; THOMPSON, D. E.

Work motivation: theory and practice.

American

Psychologist, v. 45, n. 2, p. 144153, 1990. 
KLEINBECK, U.;

WEGGE, J.;

SCHMIDT, K.

Work motivation and performance in groups. In: EREZ, M.; KLEINBECK, U.; THIERRY, $H$. Work motivation in the context of a globalizing economy. London: Lawrence Erlbaum, 2001. p. 181-196.

LAVELLE, L.

Traité des valeurs. Paris: PUF, 1951.

LOCKE, E. A.

The motivation sequence, the motivation hub, and the motivation core. Organizational Behaviour and Human Decision Processes, v. 50, p. 288-299, 1991.

LOCKE, E. A.;

LATHAN, G. P.

A theory of goal-setting and task performance. Englewood Cliffs, NJ: Prentice Hall, 1990.

MASLOW, A. H.

A theory of human motivation. Psychological Review, v. 50, p. 370-396, 1954.

MCCLELLAND, D. C.

Human motivation. Clenville: Scott Foresman, 1985.

MITCHELL, T. R.

Motivation: new directions for theory, research, and practice. Academy of Management Review, v. 7, p. 80-88, 1982.

NIETZSCHE, F.

La volonté de puissance. Paris: NRF, 1970.

OISHI, S.;

DIENER, E.

Goals, culture, and subjective wellbeing. Personality and Social Psychology Bulletin, v. 27, n. 12, p. 1674-1682, 2001.

PEARCE, J. L.;

GREGERSEN, H. B.

Task interdependence and extrarole behavior: a test of the mediating effects of felt responsibility. Journal of Applied Psychology, v. 76, p. 838-844, 1991.

PEIRÓ, J. M.;

PRIETO, F.

Tratado de psicología del trabajo. Madri: Editorial Síntesis, 1996.

PORTO, J. B.;

TAMAYO, A.

Prioridades axiológicas e regiões brasileiras: preditores de civismo organizacional. Psicologia: Organizações e Trabalho, v. 2, n.1, p. 31-61, 2002.

ROKEACH, M.

The nature of human values.

New York: Free Press, 1973. 
SCHIEHLL, E.;

MORISSETTE, R.

Motivation, measurement and rewards from a performance evaluation perspective. Revista de Administração Contemporânea, v. 4, n. 3, p. 7-24, 2000.

SCHEIN, E. H.

Psicología de las organizaciones. Englewood Cliffs, NJ: Prentice Hall, 1978.

SCHWARTZ, S. H.

Universals in the content and structure of values: theoretical advances and empirical tests in 20 countries. In: ZANNA, M. (Ed.). Advances in experimental social psychology. New York: Academic Press, 1992. v. 25. p. 1-65.

Are there universal aspects in the structure and contents of human values? Journal of Social Issues, v. 50, n. 4, p. 19-45, 1994.

Value hierarchies across cultures: taking a similarities perspective. Journal of Cross-Cultural Psychology, v. 32, p. 268-290, 2001.

SCHWARTZ, S. H.;

BILSKY, W.

Toward a universal psychological structure of human values. Journal of Personality and Social Psychology, v. 53, n. 3, p. 550-562, 1987.
Toward a theory of the universal content and structure of values: extensions and cross-cultural replications. Journal of Personality and Social Psychology, v. 58, n. 5, p. 878891, 1990.

SIQUEIRA, M. M. M.

Comportamentos de cidadania organizacional. In: SIQUEIRA, M. M. M.; GOMIDE JÚNIOR, S. ; OLIVEIRA, A. de F. (Orgs.). Cidadania, justiça e cultura nas organizações. São Paulo: Editora Metodista, 2002.

SMITH, C. A.;

ORGAN, D. W.;

NEAR, J. P.

Organizational citizenship behavior: its nature and antecedents. Journal of Applied Psychology, v. 68, p. 653-663, 1983.

STEERS, R. M.;

PORTER, L. W.

Motivation and work behavior.

New York: McGraw-Hill, 1991.

TAMAYO, A.

Hierarquia de valores transculturais e brasileiros.

Psicologia: Teoria e Pesquisa, v. 10, n. 2, p. 269-285, 1994.

Prioridades axiológicas e satisfação no trabalho. Revista de Administração, v. 35, n. 2, p. 37 47, 2000. 
Prioridades axiológicas, atividade física e estresse ocupacional. Revista de Administração Contemporânea, v. 5, n. 3, p. 127-147, 2001.

Exaustão emocional no trabalho. Revista de Administração, v. 37, n. 2, p. 26-37, 2002.

TAMAYO, A. et al.

Prioridades axiológicas e comprometimento organizacional. Psicologia: Teoria e Pesquisa, v. 17, p. 27-35, 2001.
TAMAYO, A.; SCHSWARTZ, S. H.

Estrutura motivacional dos valores humanos. Psicologia: Teoria e Pesquisa, v. 9, n. 2, p. 329-348, 1993.

VALLERAND, J. R.;

THILL, E. E.

Introduction à la psychologie de la motivation. Laval: Vigot, 1993.

VROON, V. H.

Work and motivation. New York: John Wiley \& Sons, 1964. 